\title{
An Approach to Validation of Solubility Databases for Performance Assessment
}

\author{
By I. G. McKinleyi, *, W. R. Alexander', A. Gautschi' and N. Waber ${ }^{2}$ \\ ${ }^{1}$ Nagra (National Cooperative for the Disposal of Radioactive Waste), Wettingen, Switzerland \\ ${ }^{2}$ GGWW, (Rock Water Interaction Group), University of Berne, Berne, Switzerland
}

(Received October 2, 1997; accepted in revised form March 31, 1998)

\section{Solubility / Validation / Performance assessment / $H L W / T R U$}

\begin{abstract}
Summary
This paper illustrates an approach which can be used to "validate" the solubility databases used for nuclear waste repository performance assessments. It is generally sufficient to demonstrate conservatism and, as such, validation may be undemanding in some cases. This is illustrated for the case of a concept feasibility study for HLW disposal in Switzerland. For the case where more realistic evaluation of repository performance is required, the requirements for validation may become more challenging.
\end{abstract}

\section{Introduction}

Most performance assessments for HLW repositories (and many for L/LW or TRU disposal facilities) have identified the low solubility of some elements as a key factor contributing to the safety case. In such analyses, solubility is represented rather simplistically - generally as a time-independent "solubility limit." Solubility may be defined as the maximum equilibrium concentration, in a solution of defined chemistry, which can be reached by a specific element (this definition refers to concentrations in true solution and does not consider colloids). The definition of solubility limits for performance assessment is a fairly subjective procedure which involves integration of field, laboratory and theoretical information in order to select values which may be termed "realistic" or "conservative". Realistic values are intended to provide a reasonable estimate of the maximum solubility expected for a defined "reference" water (which, in some cases, may still pessimistically overestimate actual solubility by many orders of magnitude) while conservative values are even more pessimistic estimates considering all uncertainties in the chemistry of the elements involved.

A comparison of the solubility databases used in recent HLW disposal performance assessments in a number of national programmes has indicated rather large scatters in data exist for some elements and identified lack of transparency in the procedures used to derive such databases as a particular problem [1].

\footnotetext{
* Corresponding author. E-mail: mckinleyi@ nagra.ch
}

The comparison also noted that chemical thermodynamic modelling was extensively used to develop solubility databases, with little mention of direct laboratory or field measurements.

However derived, the resulting databases need to be "validated" (in the IAEA sense of demonstrating that they are appropriate for the use envisaged). The validation process is controversial due to its inherently subjective component, resulting from the impossibility of quantifying all heterogeneity/uncertainty in a slowly evolving repository system. It is neither practical nor useful to reproduce here the debate on validation terminology - the interested reader is referred to Pescatore [2] and references therein. Nevertheless, a specific regulatory requirement for validation may be specified - as its the case in Switzerland - or this may be an implicit part of demonstrating compliance with such regulations. This paper thus illustrates a testing scheme which aims to provide sufficient confidence in critical solubility data. Particular emphasis is placed on the rile of natural analogues in assessing data applicability over the long timescales and inherent heterogeneity of the geological environment.

\section{Outline of the testing scheme}

The subjective components involved in validation procedures (as defined above) means that it is important that these are carried out in a transparent and logical manner. It is also important to note that validation applies to a specific defined use and, although the testing scheme may be generic, the detailed arguments used need to be developed on a case-by-case basis.

For any performance assessment database, the testing scheme can be focused on answering the following questions:

- Is the application clearly defined and scientifically reasonable?

- Are the theoretical arguments/models used defensible?

- What extent of validation is required to demonstrate conservatism?

- Are the selected data consistent with laboratory, field and natural analogue studies?

In the following sections, the application of this testing scheme is illustrated by taking the example of a Swiss performance assessment database for HLW 
disposal in the crystalline basement of Northern Switzerland [3]. Subsequently, the generality of specific conclusions reached for this case are discussed with reference to solubility databases derived for other uses in both Switzerland and elsewhere.

\section{Context and boundary conditions for database development}

The Kristallin-I performance assessment of HLW disposal in the crystalline basement of Northern Switzerland used a formal scenario development procedure to catalogue knowledge and assumptions about the repository system and to characterise the suite of scenarios for quantitative or qualitative analysis [4]. The concept of encapsulation of vitrified HLW in thick steel canisters which are then emplaced axially in tunnels which are backfilled with compacted bentonite leads to a very "robust" engineered barrier system (EBS). "Robust", in this context, indicates that performance is assured by well understood processes and that the system is insensitive to uncertainties or external perturbations $[3,5]$.

Solubility limits are defined [6] for use in a model which calculates release and transport of radionuclides through the compacted bentonite annulus [7]. The minimum canister lifetime of $10^{3}$ years, the large quantities of steel and bentonite (which act as chemical buffers) and the hydrogeochemical setting of the repository (ensuring low fluxes of groundwater of fairly constant chemistry) all support the assumption of fairly constant chemical conditions prevailing within the EBS for times when radionuclides are being leached from the waste [8].

Corrosion of the waste glass is known to be very slow $\left(\sim 10^{-5} /\right.$ year $)$, but the available water volume for dissolution of contained radionuclides is very small and hence precipitation of low solubility secondary phases is to be expected and is widely observed in both laboratory and natural analogue studies (see [9] and references therein).

With the further simplification that the solubility limits are defined for the most strongly buffered location (the interface between the canister and the bentonite), the assumption that such values are constant for extremely long periods of time can be justified.

\section{Defence of the arguments and models used}

Chemical thermodynamic modelling is used as a tool to support solubility database derivation [6]. The limitations of such an approach are:

1. The models inherently assume thermodynamic equilibrium, but this is not generally found in relevant groundwaters (temperatures $<\sim 50^{\circ} \mathrm{C}$ ). Unsaturated solid phases may dissolve extremely slowly and precipitation of over-saturated solids may be even slower or completely negligible.
2. Even solution phase species may not be in equilibrium - this is particularly common for redox pairs involving multiple electron transfers (e.g. $\mathrm{SO}_{4}^{2-} / \mathrm{S}^{2-}$, $\left.\mathrm{CH}_{4} / \mathrm{CO}_{3}^{2-}, \mathrm{NO}_{3}^{-} / \mathrm{NH}_{4}^{+}[10]\right)$.

3. Thermodynamic databases are rather sparse and of variable quality, even for major solution species and common minerals; data for trace elements can contain large gaps and/or very large errors.

4. Such databases generally contain data for pure solids only; in nature, trace elements are generally incorporated into more common minerals by co-precipitation or solid solution before they form pure phases (e.g. [11]).

A pre-requisite for any modelling study is consistent definition of the system to be studied. For performance assessment applications, this generally involves specification of a "reference water chemistry". The reference groundwater for the Kristallin-I study in a specific siting region is defined on the basis of extensive field studies, making careful correction for possible artefacts during sampling [12]. A review of experimental measurements of bentonite porewaters [13] complemented by an analysis of the ion-exchange and mineral dissolution reactions involved when the reference groundwater equilibrates with compacted bentonite [14] was used to derive a reference bentonite porewater.

The most critical parameters for establishing solubility limits are the Eh and $\mathrm{pH}$ values of the reference water; for the bentonite porewater, ranges for both parameters were selected based on a consideration of key buffering reactions [6]. The solubility of potentially limiting solid phases in such water was evaluated using a chemical thermodynamic model with a specially prepared database, which is fully documented $[15,16]$. These possible limits were then reviewed in the light of available laboratory data and chemical common sense (cf. Table 1) to derive a set of realistic (best estimate taking uncertainties into account) and conservative (pessimistic overestimates) solubility values for elements of interest. The solubilities of such elements were also determined in the reference groundwater, to identify any cases where precipitation at the near-field/far-field interface might occur.

With regard to the general limitations of thermodynamic modelling noted above:

1. Solid phases chosen were those likely to precipitate under expected conditions (at temperatures $<\sim 50^{\circ} \mathrm{C}$, such as simple oxides, hydroxides, carbonates, sulphates, sulphides, etc.).

2. Apart from consideration of a redox range, nonequilibrium aqueous phase speciation was not directly considered - of the elements listed in Table 1, this would be critical only for Se.

3. The presence of large gaps in the database was discussed for specific elements but used only as a qualitative basis for selection of conservative values.

4. Co-precipitation only considered directly for elements such as $\mathrm{Cm}$ and $\mathrm{Ra}$ which are present to- 
Table 1. Summary of the main considerations involved in the selection of solubility limits for key elements in the Kristallin-I performance assessment. The selection procedure is fully documented by Berner [6]

\begin{tabular}{cl}
\hline Element & \multicolumn{1}{c}{ Rationale for setting solubility limits } \\
\hline $\mathrm{Cs}, \mathrm{Ni}$ & $\begin{array}{l}\text { Very high solubility expected in the absence } \\
\text { of co-precipitation processes (arbitrary "high" } \\
\text { value selected which could be set as } 1 \mathrm{M} \text { ) }\end{array}$ \\
$\mathrm{Pa}, \mathrm{Sn}, \mathrm{Tc}$, & $\begin{array}{l}\text { Main constraint on solubility taken to be } \\
\text { formation of the metal oxides (or hydroxides); } \\
\mathrm{Np}, \mathrm{Pu} \\
\text { selected solubilities based on evaluation of } \\
\text { uncertainties in thermodynamic data, solid } \\
\text { phase crystallinity, laboratory measurements } \\
\text { and the likely formation of mixed oxides }\end{array}$ \\
$\mathrm{Pd}$ & $\begin{array}{l}\text { Expected to be effectively insoluble but, } \\
\text { conservatively, solubility assessed assuming } \\
\text { control by Pd (OH) }\end{array}$ \\
$\mathrm{Se}$ & $\begin{array}{l}\text { Assumed to be set by FeSe }{ }_{2} \text { although } \\
\text { co-precipitation with } \mathrm{S} \text { might be expected } \\
\text { in reality }\end{array}$ \\
$\mathrm{Am}$ & $\begin{array}{l}\text { Assumed to be set by Am } \mathrm{OH}\left(\mathrm{CO}_{3}\right) \\
\text { Assumed to co-precipitate with chemically }\end{array}$ \\
$\mathrm{Cm}, \mathrm{Ra}$ & $\begin{array}{l}\text { similar elements present in much higher } \\
\text { quantities (Am and Ba/Sr/Ca, respectively) }\end{array}$ \\
\hline
\end{tabular}

gether with much larger inventories of elements of similar chemistry.

\section{Validation requirements to ensure "conservatism"}

Within performance assessment (PA), conservatism is defined in terms of involving pessimistic assumptions (i.e. which tend to overestimate consequences in terms of releases or resultant doses) to compensate for uncertainty. It needs to be very clear in the context of the models involved what assumptions really are conservative.

Because of the extremely low hydraulic conductivity and microporous nature of compacted bentonite, solute transport occurs predominantly by diffusion and is only significant for species in true solution. For the Kristallin-I near-field model, the concentration gradient over the bentonite thus drives releases and hence any process which increases solute concentration at the inner bentonite surface will conservatively increase the release flux. In such a "groundwater-release" scenario, which is the focus of the Kristallin-I performance assessment, the treatment is clearly conservative for elements for which no solubility limit is defined (Cs, Ni) and no validation for this case is required. The demonstration that colloid transport does not occur through the backfill is critical to this argument. Otherwise, unlimited solubility is not necessarily conservative because "precipitated" colloids could be more mobile than species in true solution. A very clear system understanding is thus essential to an assessment of conservatism.
In principle, the defined solubility limits for all other elements need to be validated, but the effort needed depends very much on the contribution of solubility to the safety case. For example, a very high solubility limit for $\mathrm{Nb}$ is chosen for the database $\left(10^{-3} \mathrm{M}\right)$ - based on very limited data for $\mathrm{Nb}_{2} \mathrm{O}_{5}$ due to the uncertainty in the knowledge of the chemistry of this element [6]. Taking the $\mathrm{Nb}$ inventory at the time of earliest canister failure, however, would lead to a calculated release rate of only $2 \times 10^{-7}$ moles/year by taking the constraints set by glass corrosion rate into account. Scoping calculations illustrate that, for this element, low inventories (plus relatively short half-lives of important radioisotopes) plus low corrosion rate of the glass matrix are the key components of the argument for the performance of the EBS and any reference to solubility involves a more qualitative invocation of the multi-barrier principle. For such a usage, very little validation effort is required.

A somewhat more marginal case is presented by $\mathrm{Ra}$, where the selected solubility $\left(10^{-10} \mathrm{M}\right)$ is only slightly above the molar release rate from the glass ( $\mathrm{Ra}$ inventory at $10^{3}$ years is $2.4 \times 10^{-7}$ moles but increases by a factor of 40 or so due to ingrowth from long-lived parents). Other marginal elements include $\mathrm{Am}, \mathrm{Th}, \mathrm{Pa}$ and $\mathrm{Bi}$.

For other elements, such as U, Np, Pu, Tc, Pd and $\mathrm{Se}$, solubility may reduce releases significantly and contributes directly to the safety case. The greatest need for validation is thus identified for such elements.

\section{Consistency with measured data}

In all cases, the selected solubility limits were compared to measured concentrations in laboratory experiments and concentrations observed in natural systems, but this was more in the sense of a simple "reality check" to identify any gross discrepancies rather than as a strict attempt to test the resulting database.

To illustrate a procedure for more systematic validation of the performance assessment solubility database, the specific case of $U$ is selected. This element is assumed to be limited by $\mathrm{UO}_{2}$ precipitation and assigned a realistic solubility of $10^{-7} \mathrm{M}$ and a conservative value of $7 \times 10^{-5} \mathrm{M}$ for reference conditions. The relatively large inventory of $U$ would, by comparison, lead to a release rate from the glass of $\sim 10^{-4}$ moles/ year.

As discussed by Berner [6], an extensive literature of laboratory measurements of $\mathrm{UO}_{2}$ solubility exist, but relatively few studies have been carried out under representative redox conditions. Relevant data show a very wide scatter $\left(\sim 10^{-10}-10^{-4} \mathrm{M}\right)$, reflecting difficulties of redox control and variable crystallinity and stoichiometry of the " $\mathrm{UO}_{2}$ " involved. Nevertheless, the selected values for the database lie in the upper part of this range. 
Evidence for the formation of crystalline U minerals under relevant natural conditions can be found in low temperature mineralisation - particularly associated with redox fronts. The environments are good analogues, as $U$ is present in the waste form in the VI oxidation state and is subsequently reduced by $\mathrm{Fe} /$ Ferrous minerals to the IV form. Extensive studies at Poços de Caldas [17] show the formation of pitchblende $\left(\mathrm{U}_{3} \mathrm{O}_{8}\right)$ at the reducing side of relatively nearsurface redox fronts. Even though measured groundwaters are less reducing than expected in a HLW repository, concentration in a wide range of groundwaters in contact with the uranium mineralisation have concentrations $<10^{-7} \mathrm{M}$ (consistent with thermodynamic modelling assuming solubility control by pitchblende - [11]).

In Switzerland, on a smaller scale, formation of uranite $\left(\mathrm{UO}_{2}\right)$ in association with other $\mathrm{U}(\mathrm{IV})$ oxides such as brannerite $\left(\mathrm{UTi}_{2} \mathrm{O}_{4}\right)$, and uraniferous leucoxene $\left(\mathrm{nTiO}_{2}: \mathrm{UO}_{2}\right)$ is observed in redox haloes from both Permian red beds and crystalline rocks [18]. The presence of such crystalline phases is consistent with measured concentrations in deep Swiss groundwaters which fall in the range of $2 \times 10^{-11}-5 \times 10^{-9}$ molar. The higher end of this range is, indeed, somewhat suspect due to the great difficulty of sampling such waters and avoiding, or correcting for, contamination by surface waters or drilling fluids.

A recent study of the hydrochemical data from the Canadian URL (Underground Rock Laboratory) is also relevant [19]. Although detailed $U$ mineralogy is not reported, the clear trend of decreasing $U$ concentration with decreasing depth and more reducing conditions strongly indicate precipitation of phases which reduce the aqueous $U$ concentration to $\sim 10^{-10}-$ $10^{-9} \mathrm{M}$. Both in this study and hydrochemical analyses of Northern Switzerland [12], $U$ concentration is shown to be a good indication of effective redox conditions - strongly supporting the assumption of relatively rapid thermodynamic equilibrium for this element.

Taken together, the consistency of the observation of crystalline oxide formation and measured concentrations in old groundwaters make a convincing case for a realistic solubility limit in the range of $\sim 10^{-10}-$ $10^{-9} \mathrm{M}$. The range selected for the Kristallin-I performance assessment database can therefore be reasonably considered validated in that it will overestimate the $U$ solubility by $3-5$ orders of magnitude - an enormous safety buffer which might even be considered over-conservative!

It must be emphasised that such a conclusion can be reached only on the basis of an understanding of the reasons for the discrepancies between the widely scattered laboratory/thermodynamic data and the consistent picture presented by deep, reducing groundwaters - and confidence that the latter more closely represent the situation in the repository considered (assured low-flow reducing conditions where well crystallised phases may form).

\section{Application of the validation procedure to other cases}

The rather clear case that can be made for the Kristallin-I example above reflects the facts that

- The engineered barrier system for HLW forms a stable, well-buffered, geochemical system.

- An extensive system understanding has been built up over 2 decades of repository concept development and site characterisation work.

- The strengths and weaknesses of chemical thermodynamic modelling are well understood and this tool is complemented by an integrated appraisal of laboratory and natural system (or analogue) data.

The testing scheme presented above can, however, be generally applied to identify potential areas of improvement of the validation "case" or requirements for validation in other performance assessments.

The defence of the $U$ database value was described above and similar arguments can also be made for the Kristallin-I solubilities selected for other elements with relatively simple chemistry and extensive environmental databases. The case for validation is weaker for some elements which are present in the environment in trace quantities only (e.g. $\mathrm{Pu}, \mathrm{Tc}$ ) although, for these particular examples, there is a wide range of laboratory evidence supporting their low solubility under reducing conditions, which is supported by weaker documentation of their low mobility under relevant environmental conditions. A particular problem among the safety-relevant elements identified as solubility controlled [3] is Se, which is calculated to have low solubility but the reduction of which is known to be very slow under low-temperature, inorganic conditions. There is certainly evidence for the reduction of $\mathrm{SeO}_{3}^{2-}$ (or $\mathrm{SeO}_{4}^{2-}$ ) by sulphate reducing bacteria - which would probably be present in a repository environment. Nevertheless, this would be an element where evidence to build a stronger case for validation would be useful.

As far as the utilisation of the solubility limits is concerned, other waste types are certainly more problematic. Transuranic-containing or long-lived intermediate-level waste (TRU/ILW) can contain significant inventories of important radionuclides, but their chemistry may be very complex (e.g. when wastes contain large quantities of organic material and/or when cementitious material are used as immobilisation matrices/backfills). In such a case, it may not be evident that "reference conditions" can be unambiguously defined or that such conditions are relatively constant over the period of relevance for the performance assessment. In such cases, definition of simple solubility may have to be expressed as a function both of location within the EBS and of time.

The defence of the database development approach is relatively easy for Kristallin-I, where the database production is documented in detail [6] and the limitations of the modelling tools used are clearly acknowledged. This is certainly less evident in other 
assessments which appear to put much more weight on the geochemical models used, e.g. [20] or which use a much less transparent "expert elicitation" methodology, e.g. [21]. This latter example is a case where a probabilistic performance assessment methodology is used and hence solubilities are defined as a probability distribution function (pdf). In general, the derivation of such functions seems less transparent than conservative/realistic pairs (or best guess and range) which are used for deterministic performance assessments complemented by sensitivity analysis. It is not at all clear to the authors how pdfs could be validated (using analogues or any other methods) and this may be an area where some further effort to clarify options would be justified.

As the aim of the Kristallin-I performance assessment described above was simply to demonstrate concept feasibility, it is acceptable to select solubility limits which are grossly over-conservative. If, however, an assessment is aimed at evaluating different options or concepts (e.g. different host rocks or different EBS designs), such an approach may not be appropriate. In this case, over conservatism may mask real differences in expected performance of alternatives and hence the requirements for validation may be very much tougher. It is evident from the $U$ example considered above that the database considered is far from realistic even if it can be defended as conservative for the application involved. On the other hand, if the use of the database is only to compare variants and not to demonstrate safety, less strict requirements on validation may be involved if a separate safety analysis is used for the latter purpose. In any case, the effort needed for validation is clearly case-specific.

The case for validation is certainly weaker for other waste types - particularly cementitious wastes which produce a hyperalkaline near-field environment. Thermodynamic databases for such conditions are particularly sparse and their limited applicability is suggested by the long-term persistence of thermodynamically unstable amorphous or gel phases under lower temperature conditions [22]. This is combined with rather limited databases of both experimental and field measurements of aqueous concentrations of trace species. This would certainly be an area where more focused effort might be justified.

More generally, it can be noted that although a wide range of groundwater geochemistry and mineralogical data are available for relevant environments, their direct use to support validation studies is limited by:

1. Poor quality of hydrochemical data; very rigorous sampling procedures are needed to obtain deep groundwaters without risking considerable contamination - particularly for trace elements. All chemical analyses of such waters should be appraised to check for such effects [12]. For example, it was noted that the reported sulphate concentration in deep groundwaters in Northern Switzerland dropped by a factor of 6 following improvements in sampling techniques [9].
2. Lack of information on trace minerals; in addition to identifications of their presence, detailed morphological or isotopic studies to indicate their mode of formation and likely recent dissolution/precipitation and chemical analysis to determine the presence of trace elements in co-precipitations should be carried out [18]. An improvement through better focus of analytical programmes could provide a valuable resource to support future performance assessments.

\section{Conclusions}

The process illustrated above indicates that, although the rôle of solubility limits in performance assessment is often emphasised, the values chosen may play a critical rôle for very few elements in the specific case of HLW disposal.

The values selected are often extremely conservative - many orders of magnitude above measured concentrations in laboratory or analogue systems. However, the reasons for the discrepancy between selected limits and measured concentrations are generally well understood. In such cases, the databases are "valid" they can be assured to over-predict the releases in a repository system. Indeed, in several cases, it could be argued that selected values are over-conservative.

Application of this testing scheme to other performance assessments may help to focus effort for the validation of the safety databases used.

\section{References}

1. McKinley, I. G., Savage, D.: Comparison of solubility databases used for HLW performance assessment: J. Contaminant Hydrol. 21, 335-350 (1996).

2. Pescatore, C.: Validation: the eluding definition; Radioact. Waste Manag. Environ. Restorat. 20, 13-22 (1995).

3. Nagra: Kristallin-I - Safety Assessment Report, Nagra Technical Report series, NTB 93-22E, Nagra, Wettingen, Switzerland (1994).

4. Sumerling, T. J., Grogan, H. A., Smith, P. A.: Scenario Development for Kristallin-I; Nagra Technical Report series, NTB 93-13, Nagra, Wettingen, Switzerland (1998), in press.

5. McCombie, C., McKinley, I. G., Zuidema P.: Sufficient Validation: The Value of Robustness in Performance Assessment and System Design. In GEOVAL-1990, Symposium on Validation of Geosphere Flow and Transport Models, pp. 598-610. OECD/NEA. Paris, France (1991).

6. Berner, U.: Kristallin-I - Estimates of solubility limits for safety-relevant radionuclides; Nagra Technical Report series, NTB 94-08, Nagra, Wettingen, Switzerland (1994).

7. Grindrod, P., Williams, M., Grogan, H., Impey, M.: STRENG - A source-term model for vitrified high-level waste; Nagra Technical Report series, NTB 90-48, Nagra, Wettingen, Switzerland (1990).

8. McKinley, I. G.: The geochemistry of the near field; Nagra Technical Report series, NTB 84-48, Nagra, Wettingen, Switzerland (1985).

9. Alexander, W. R., McKinley, I.: The chemical basis of the Swiss high-level radioactive waste disposal concept (nearfield). In Chemical containment of wastes in the geosphere (ed. R. Metcalfe), Geol. Soc. Eng. Spec. Publ. (1998), in press. 
10. Lindberg, R. D., Runnells, D. D.: Groundwater redox reactions - An analysis of equilibrium state applied to Eh measurements and geochemical modelling; Science 225, 925927 (1984).

11. Bruno, J., Cross, J. E., Eikenberg, J., McKinley, I. G., Read, D., Sandino, A., Sellin, P.: Testing models of trace element geochemistry at Poços de Caldas; J. Geochem. Explor. 45, 451-470 (1992).

12. Pearson, F. J., Scholtis, A.: Chemistry of reference waters of the crystalline basement of Northern Switzerland for safety assessment studies; Nagra Technical Report series, NTB 9307, Nagra, Wettingen, Switzerland (1993).

13. Grauer, R.: The chemical behaviour of montmorillonite in a repository backfill - Selected aspects; Nagra Technical Report series, NTB 88-24E, Nagra, Wettingen, Switzerland (1990).

14. Curti, E.: Modelling bentonite porewaters for the Swiss high-level radioactive waste repository; Nagra Technical Report series, NTB 93-45, Nagra, Wettingen, Switzerland (1993).

15. Pearson, F. J., Berner, U.: Nagra thermo-chemical data base - I. Core data; Nagra Technical Report series, NTB 91-17, Nagra, Wettingen, Switzerland (1991).

16. Pearson, F. J., Berner, U., Hummel, W.: Nagra thermochemical data base - II. Supplemental Data 05/92; Nagra Technical Report series, NTB 91-18, Nagra, Wettingen, Switzerland (1992).
17. Waber, N., Schorscher, H. D., Peters, T.: "Poços de Caldas Report No. 2 - Mineralogy, petrology and geochemistry of the Poços de Caldas analogue study sites, Minas Gerais, Brazil"; Nagra Technical Report series, NTB 90-20 (SKB TR 90-11/UK DOE WR 90-042) Nagra, Wettingen, Switzerland (1991).

18. Hofmann, B. A.: Reduction spheres in hematitic rocks from Northem Switzerland: Implications for the mobility of some rare elements; Nagra Technical Report series, NTB 89-17, Nagra, Wettingen, Switzerland (1990).

19. Gascoyne, M.: Evolution of redox conditions and groundwater composition in recharge/discharge environments on the Canadian Shield. Hydrogeol. J. 5, 4-18 (1997).

20. PNC: Research and development in geological disposal of high-level radioactive waste - First progress report; PNC TN 1410 93-059, PNC, Tokyo, Japan (1992).

21. Wilson, M. L. et al.: Total system performance assessment for Yucca Mountain - SNL second iteration (TSPA-1993); Sandia report SAND 93-2675, SNL, New Mexico, USA (1994).

22. Linklater, C. M., Albinsson, Y., Alexander, W. R., Casas, I., McKinley, I. G., Sellin, P.: A natural analogue of high pH cement pore waters from the Maqarin area of northern Jordan: comparison of predicted and observed trace element chemistry of uranium and selenium. J. Contaminant Hydrol. 21, 59-69 (1996). 